\title{
Article
}

\section{Avoiding Gender Exploitation and Ethics Dumping in Research with Women}

Cook, Julie

Available at http://clok.uclan.ac.uk/27818/

Cook, Julie ORCID: 0000-0002-6391-5430 (2020) Avoiding Gender Exploitation and Ethics Dumping in Research with Women. Cambridge Quarterly of Healthcare Ethics, 29 (3). pp. 470-479. ISSN 0963-1801

It is advisable to refer to the publisher's version if you intend to cite from the work. http://dx.doi.org/10.1017/S0963180120000213

For more information about UCLan's research in this area go to

http://www.uclan.ac.uk/researchgroups/ and search for <name of research Group>.

For information about Research generally at UCLan please go to http://www.uclan.ac.uk/research/

All outputs in CLoK are protected by Intellectual Property Rights law, including Copyright law. Copyright, IPR and Moral Rights for the works on this site are retained by the individual authors and/or other copyright owners. Terms and conditions for use of this material are defined in the policies page. 


\section{Avoiding Gender Exploitation and Ethics Dumping in Research with Women $^{1}$}

(Short title: Gender exploitation and ethics dumping)

Julie Cook

Research Fellow

Faculty of Health \& Wellbeing

University of Central Lancashire (UCLan)

Preston, PR1 2HE

UK.

01772892549

Jcook11@uclan.ac.uk

Acknowledgement

This paper was developed as part of the TRUST project funded by the European Commission Horizon 2020 programme, grant agreement number 66477 . I would also like to thank Kate Chatfield and Doris Schroeder for their comments. 


\section{Abstract}

There is a long history of women being under-represented in biomedical and health research. Specific women's health needs have been, and in some cases still are, comparatively neglected areas of study. Concerns about the health and social impacts of such bias and exclusion have resulted in inclusion policies from governments, research funders, and the scientific establishment since the 1990s. Contemporary understandings of foregrounding sex and gender issues within biomedical research range from women's rights to inclusion, to links between human rights, women's health and sustainable development, and the increasing scientific and funding expectation for studies to consider the sex (biological) and gender (cultural) implications of research design, results and impact. However, there are also exploitation issues to consider when foregrounding the inclusion of women as research participants, especially for research ethics committees and institutional review boards. A hidden risk is that exploitative research designs and practices may be missed, particularly by reviewers who may not have a nuanced understanding of gender-based harm. Utilising contemporary case studies of ethics dumping, this paper highlights some of the concerns, and makes recommendations for IRBs/research ethics reviewers to help ensure that essential research is undertaken to the highest ethical standards.

\section{Introduction}

Since the 1960s there has been an increasing focus on the inclusion of women's health needs in research. ${ }^{1}$

There is a long history of women being under-represented in biomedical and health research. Specific women's health needs have been, and in some cases still are, comparatively neglected areas of study (e.g. endometriosis ${ }^{2}$ ). But until the late $20^{\text {th }}$ century researchers often excluded women from clinical trials on the simultaneous (if conflicting) bases that women would have the same responses to drugs as men, ${ }^{3}$ and that women were confounding subjects because of fluctuating hormone levels. ${ }^{4}$

It is now well-understood that sex differences are an important variable in health, from the genetic or cellular to the organismal and behavioural levels, and that sex differences are observable in various disease states. For example, incidence, signs and symptoms of lung cancer, cardiovascular disease and sexually transmitted infections (STIs) can affect women differently from men. Outcomes and responses to treatment also vary by sex, and physiology can translate into differences in pharmacokinetics and pharmacodynamics for specific drugs. ${ }^{5}$ Scientifically, sex is generally understood as classification by chromosomal complements, with gender seen as a cultural dimension of sex expression and response. ${ }^{6}$ Health inequalities due to such gendered cultural and social factors are also well-recognised. ${ }^{7}$

Concerns about the health and social impacts of such bias and exclusion in research have resulted in inclusion policies from governments, research funders, and the scientific establishment since the 1990s. ${ }^{8}$ The Gendered Innovations in Science, Medicine and Health, and Engineering and Environment Project, through Stanford University, the European Commission and the U.S. National Science Foundation, identifies three strategic approaches to gender equality over the past several decades:

1. "Fix the Numbers of Women" focuses on increasing women's participation. 
2. "Fix the Institutions" promotes gender equality in careers through structural change in research organizations.

3. "Fix the Knowledge" or "gendered innovations" or the "gender dimension" stimulates excellence in science and technology by integrating sex and gender analysis into research. ${ }^{9}$

This strategy has formed the focus of debates and policies, as well as the literature about the necessity to include women and women's needs in biological and health research. These developments have been supported by the intersection of two global movements. The first is the movement to address gender inequality. At an international policy level this has been largely driven by the continued implementation of the Platform for Action that emerged from the 1995 United Nations (UN) Development Programme Fourth World Conference on Women, in Beijing, "10 "which remains the most comprehensive document of the world's commitment to women's rights". ${ }^{11}$ In 2010, UN Women was established as a single recognized driver to work for the elimination of discrimination against women and girls, empowerment of women, and achievement of equality between women and men as partners and beneficiaries of development, human rights, humanitarian action and peace and security. ${ }^{12}$

The second movement is the need to achieve sustainable development, initiated globally through the Convention on Biological Diversity ${ }^{13}$ at the 1992 Rio Earth Summit, and also addressed through the UN Millennium Development Goals (2000 - 2015), and the 2016-30 Sustainable Development Goals (SDGs, also known as Agenda 30). These two movements have become increasingly entwined, from grass roots activism through to national and international agendas, ${ }^{14}$ such that it is now recognised at the highest global level, as well as by many citizens worldwide, that sustainable development cannot be achieved without the full empowerment of women and girls (SDG $5^{15}$ ).

Contemporary understandings of foregrounding sex and gender issues within biomedical research therefore range from women's rights to inclusion in research studies, ${ }^{16}$ to the links between human rights, ${ }^{17}$ women's health ${ }^{18}$ and sustainable development, ${ }^{19}$ and the increasing scientific and funding expectation for studies to consider the sex (biological) and gender (cultural) implications of research design, results and impact ${ }^{20,21,22}$. However, there are also gender exploitation issues to consider when women are included in research. For example, Carly Drake and Jacqueline Gahagan argue that using women as health promotion change agents in HIV interventions aimed at men creates burdens for women without benefits, and reinforces gender stereotypes which are differentially harmful to both the women, and the men concerned. ${ }^{23}$

In recent years the need to achieve equity in international research has become a pressing concern. The term 'ethics dumping' was first used by the European Commission to characterise research carried out by institutions from high income countries (HICS) in low or middle-income countries (LMICs) in a way which would not be accepted in the home settings (e.g. Europe or USA). ${ }^{24}$

"Ethics dumping" occurs mainly in two areas. First, when research participants and/or resources in low- and middle-income countries (LMICS) are exploited intentionally, for instance because research can be undertaken in an LMIC that would be prohibited in a high-income country. Second, exploitation can occur due to insufficient ethics awareness on the part of the researcher, or low research governance capacity in the host nation..$^{25}$

Questions about how to counter these unethical research practices have become the subject of international attention, building on existing guidelines such as the Declaration of Helsinki ${ }^{26}$ and the 
Council for International Organizations of Medical Sciences CIOMS Guidelines ${ }^{27}$ to produce new recommendations for good practice. ${ }^{28}$

A 2018 book, Ethics Dumping: Case Studies from North-South Research Collaborations, ${ }^{29}$ provides evidence of ethics dumping across six themes in international research; vulnerable populations, clinical trials, benefit sharing, animal research, new and emerging technologies (NEST), and ethical and governance processes. Ethics Dumping does not explicitly apply a gender perspective to its themed analysis of risks for ethics dumping, but in this paper I utilise two cases from the anthology to discuss gender issues raised by studies which only include female research participants.

I argue that a hidden risk of foregrounding the inclusion of women as research participants is that exploitative research designs and practices may be missed, particularly by ethics reviewers who may not have a nuanced understanding of gender-based harm. Enriching our understanding of the patterns which underlie ethics dumping can support more robust ethics review of research, and protect female research participants from exploitation, in a world where as a result of progressive policies they are more likely than ever to be recruited as participants in biomedical research.

\section{Human Food Trial of a Transgenic Fruit}

This case study ${ }^{30}$ discusses the controversial proposed trial of a transgenic fruit in North American university students, who would be paid to eat a strain of genetically altered bananas destined for use in a LMIC (Uganda). It locates the risks to potential participants in the context of tensions between the concepts of food security ${ }^{31}$ and food sovereignty, ${ }^{32}$ and makes recommendations regarding ethics in agricultural research and the requirement to match research to local (i.e. proposed destination) needs. However, although the case study raises the specific risks of unknown human health impacts to female participants of childbearing age, it does not ask why only female students were invited to take part in the trial in the first place. This gap is also evident in public communications from 'AGRA watch', a grassroots, Seattle-based group challenging the Bill and Melinda Gates Foundation's (BMGF) agricultural programs in Africa, who organised a petition against the study in 2016. A quote provided in the 'AGRA watch' literature from a molecular biologist based at the Salk Institute that "...a feeding trial in people, especially women, should not be allowed.", largely passes without further comment. ${ }^{33}$

Initial local press reports on the controversy noted that the invitation was to female students, yet only discussed opponents' concerns in terms of generic risks to human health. The case study reports that the lead researcher publicly stated in her 'defence' that she had previously led a study with women eating food modified to contain high levels of beta-carotene. However, the published results of that original study also provide no justification for including only women as participants, and further, the original study discusses and compares the results only in terms of "healthy adults". ${ }^{34}$

Interestingly, journalists comment in a report on the banana study that, "It's not clear why they had to be female, but our guess is that pregnant or nursing women and their children are especially vulnerable [to] vitamin A deficiency" ${ }^{35}$ Maybe bioethicists and research ethics reviewers should be concerned that this basic question about the design of the study seems only to have been addressed by the "guesses" of journalists.

More recent local press coverage of the controversy has dropped any references to the gender of the student participants at all. ${ }^{36}$ So it seems that specific concerns about the inclusion of women in the trial have been increasingly backgrounded in favour of discussion about risks to humans in general, when in fact the risks here were only to women. One might think this a strategic 
campaigning failure by those opposed to the trial, but of greater concern is the lack of bioethical attention to this not insignificant detail.

A clue lies in the suggestion by the journalists quoted above. The 'banana 21 ' project $^{37}$ was initiated by Queensland University of Technology in Australia with funding from BMGF. The project website and statements from the US university conducting the trial all rightly stress the global public health burden of vitamin A deficiency in babies and pre-school children, which is most prevalent in Africa and South East Asia. The World Health Organization (WHO) describes the health burden for pregnant women globally in high risk areas. ${ }^{38}$ So there are undoubtedly important bioethical questions to be asked about who would benefit most from successful solutions to address this problem, which seems to occur predominantly in LMICs. However, there seems to be a conceptual jump between global maternal and child health and mortality concerns, and the automatic and largely unquestioned inclusion of healthy women in a HIC as ideal testing grounds for the transgenic bananas.

This potentially raises an interesting reversal of the traditional bioethical critique of the use of populations in LMICs to test innovations that will predominantly benefit HIC populations. ${ }^{39}$ However, I am not arguing here that these tests should take place in a different international setting with more vulnerable participants, although there may well be arguments for conducting the trials in the country the fruit is intended for. Here, I would like to explore the conceptual shift that assumes the female American students were appropriate participants for this study, asking how this lack of gender awareness impacts on the design and ethical approval of research studies.

Leaving aside issues of how well the participants were informed about the proposed study and the quality of their consent, it is important to recall that students in an institution are by definition potentially vulnerable participants due to their hierarchical/subordinate relationship with researchers at that (or other) institutions. ${ }^{40}$ Therefore there are questions here about whether this research could have been more widely conducted in the general population, or if it was targeted at students, as is still so often the case, for ease of recruitment. ${ }^{41,42}$

A USD $\$ 900$ fee was offered for participation, so in a student population which is (relatively) impoverished compared to the general population, there are potential issues of inducement here, again denoting vulnerability. It is well-documented that in any setting globally, there is a gender wealth gap, and in the USA today, "Based on median annual earnings, a woman working full time, year-round typically earns only 79 cents for every dollar earned by her male counterpart. The 21percent difference in earnings (or 21 cents on the dollar) is known as the "gender pay gap". ${ }^{43}$ This means that any financial inducement is likely to be more of an inducement for a woman than a man, even in a HIC. This problem does not disappear if only women are to be recruited; instead it leaves us with a situation where all of the potential participants are at risk of inducement.

Attention to these questions at ethics review might have headed off some of the resulting highprofile controversy, so there are pragmatic concerns here too, specifically in the context of the institutional protection role of Institutional Review Boards (IRBs) in the US.

Raising a general concern about the exploitation of women in research may initially seem misplaced regarding this small study in a HIC. However, the overall 'banana 21' project to release genetically modified foods into an LMIC has enormous implications. The controversial transgenic banana trial was not a traditional clinical trial, yet given the gender issues it raises, one might propose that ethics review processes should ask more questions about gender variety/balance in research participation and how this impacts on risk/benefit assessments. 


\section{Cervical Cancer Screening In India}

A second case study in Ethics Dumping describes three linked cluster-randomized clinical trials that took place in India between 1998 and 2015 to determine whether trained health workers could conduct cervical cancer screening using cheaper visual methods of screening than cytology (Pap smear) to reduce the incidence and mortality of cervical cancer. ${ }^{44}$ Approximately 374,000 poor and socially disadvantaged women were included, with 141,000 of them allocated to a control group of no screening; in two of the trials they simply received one-off health education on the causes of cervical cancer, and information about available services, in the third there was no control group intervention, and outcomes of incidence or mortality of cervical cancer were subsequently collected through data monitoring. The trials are enormously controversial as known and effective methods of screening (Pap smear) were withheld from the high-risk control group, despite being available in all major hospitals, and having been recognised as the standard of care in India since the 1970s. However, due to the lack of universal availability of Pap smear under a government programme, the trials (mis)construed the existing standard of care for the control group as no screening (no active care). To date 254 women in the control arm are known to have died due to undetected and untreated cervical cancer.

This is a classic and tragic story of ethics dumping, which demonstrates the harm caused to participants in LMICs by research designs that would not be permitted in the country of the funders, in this case the USA (BMGF and National Institutes of Health (NIH)), and France (International Agency for Research on Cancer (IARC)). The case study authors argue that a catalogue of scientific and regulatory weaknesses and structural and economic inequities combined to lead to the violation of a range of rights for the control group participants, including the right of access to the highest available standard of healthcare, and the universal right to life.

In this case study, it is self-evident that the subject of the study is global women's health needs, and that all the participants were necessarily women. Therefore a gender analysis might at first glance seem superfluous. Indeed the researchers' defences of their methodology have relied on this claim to justify their work. Who would not support investigation into more accessible methods of cervical cancer screening for vulnerable women in LMICs which struggle to provide universal access to the acknowledged standard of care? However, if we take a step back this case raises crucial issues about women's participation in such studies, with strong echoes of the ethics debates over maternal-fetal transmission of HIV trials in the 1990s. ${ }^{45,46}$

The participants in the cervical cancer trials were poor, uneducated women at risk of increased mortality and morbidity from a range of preventable health conditions, without universal access to healthcare, and so were vulnerable. ${ }^{47}$ But this vulnerability is due to pre-existing structural inequalities, and it is widely recognised in the international sustainable development agenda that these have a powerful gender dimension. For example, the UN Committee on the Elimination of Discrimination against Women states:

Globally, and with few exceptions, rural women disproportionately experience poverty and exclusion. They face systemic discrimination in accessing land and natural resources. Even when formally employed, they are more often engaged in work that is insecure, hazardous, poorly paid and not covered by social protection. They are less likely to be educated and are at higher risk of being trafficked and forced into labour, as well as into child and/or forced marriage and other harmful practices. $^{48}$ 


\section{The impact of gender on vulnerability}

Building on Doris Schroeder and Eugenijus Gefenas' definition of vulnerability, ${ }^{49}$ I have previously argued that issues of gendered vulnerability in research can be defined as the probability of incurring harm while lacking protection mechanisms due to gendered inequalities:

There is a need for a nuanced, contextualised understanding of gender-based vulnerability among population groups as a basis for developing responses that give special protection to the most vulnerable. If the poor are at the bottom of the social ladder, poor women are on the lowest rung. ${ }^{50}$

The above two case studies show contrasting settings in which women are rendered differentially vulnerable to exploitation in research due to pre-existing and structural gender-based inequalities. This reveals that there is a need to address the wider gender issues raised by the context of specific research studies, ${ }^{51}$ which in turn requires sensitivity to the gendered dimension of the vulnerability of research participants of all types (direct, controls etc.).

Ethics guidelines and the practical work of research ethics committees constantly require us to consider differentials amongst participants when evaluating a study proposal. But a homogenous participant group can mask such differentials.

Where research takes place in a context of persistent and systematic gender inequality, all-women participant groups can obscure the ways in which research itself can exploit, contribute to and even exacerbate those inequalities. ${ }^{52}$ It is easy to miss the 'red flags'. But consciously applying a gender lens can facilitate this process, and help us to step back and ask - if the participants are all women, then where will we find the gender-based vulnerabilities that may lead to ethical problems? This can help us to resist, for example, the leveraging of genuine health needs (in both cases here, of poor LMIC women) to mask the exploitation of female research participants.

In the case of the 'banana 21 ' trial, such an approach might have challenged the study design and avoided a controversy. In the cervical cancer trials, although it is obvious why only women would be recruited to such studies, that the participants are all women still works as an indicator ('red flag') for their potential vulnerability to exploitation; and this enables us to ask searching questions about a trial where there is not only no possible benefit to the control group, but a potential for actual harm, including loss of life.

Analysing and connecting themes of gender inequality in case studies, such as the two discussed in this paper, can therefore support researchers and bioethicists to ask wider and deeper questions about gender justice in research.

\section{Conclusion and Recommendations}

The worldwide movement towards identification of and investment in women's health needs and the inclusion of women as participants in biomedical research should not ignore continuing issues of exploitation. In the 1990s, bioethical debates about maternal-fetal HIV transmission studies were "embedded in the far broader debate on the conditions under which research in Third World nations should take place". ${ }^{53}$ We now live in a time where ethics dumping in international research has become a paramount concern. So perhaps it is time that discussions about the gendered ethical issues raised by these case studies also became embedded in this broader debate on the conditions under which research on women only should take place. 


\section{IRBs/reviewers should:}

- Note single gender cohorts as a 'red flag':

There should be an expectation that researchers will include a justification for single gender cohorts in their application for ethics approval.

- Feel confident to ask questions or challenge the appropriateness of a single gender research design: what research purpose does this serve, and what benefits could it have for this gender?

- Relate ethics approval for single gender cohorts to the mitigation of risks in the research context:

Taking gender inequity as a starting point, in what ways are this participant group vulnerable in their community or society - how might participation in the proposed study exploit those conditions, or exacerbate them?

IRB/ethics review should (where appropriate) consider opinions or input from local/host ethics committees, and patient and public involvement in research design, including advocates/representatives, to help assess and mitigate potential genderbased harms for research participants.

\section{Endnotes}

\footnotetext{
${ }^{1}$ European Commission \& Stanford University. Research \& Innovation Science With And For Society. Gendered Innovations in Science, Health \& Medicine, Engineering, and Environment. Policy Timeline. Available from http://ec.europa.eu/research/swafs/gendered-innovations/index en.cfm?page=index.html (last accessed 4 March 2019).

${ }^{2}$ Adamson GD, Kennedy S, Hummelshoj L. Creating Solutions in Endometriosis: Global Collaboration through the World Endometriosis Research Foundation. Journal of Endometriosis and Pelvic Pain Disorders 2010; 2(1):3-6.

${ }^{3}$ Mazure CM, Jones DP. Twenty years and still counting: including women as participants and studying sex and gender in biomedical research. BMC Women's Health 2015; 15(94):1-16.

${ }^{4}$ Liu KA, Dipietro Mager NA. Women's involvement in clinical trials: historical perspective and future implications. Pharmacy Practice 2016. 14(1):708.

${ }^{5}$ See note 4. Liu, Dipietro Mager 2016: 1-2.

${ }^{6}$ See for example, Wizemann TM, Pardue MHL, editors. Institute of Medicine Board on Health Sciences Policy Committee on Understanding the Biology of Sex and Gender Differences. Exploring the biological contributions to human health and does sex matter? Washington DC. Institute of Medicine, 2001.

${ }^{7}$ Moss NE. Gender equity and socioeconomic inequality: a framework for the patterning of women's health. Social Science \& Medicine 2002. 54(5):649-661.

${ }^{8}$ See note 1 . European Commission \& Stanford University.

${ }^{9}$ See note 1. European Commission \& Stanford University.

${ }^{10}$ UN Women. Fourth World Conference on Women 1995. Available from: http://www.un.org/womenwatch/daw/beijing/platform/ (last accessed 4 March 2019).

${ }^{11}$ Desai M. Hope in hard times: Women's empowerment and human development. Human Development Research Paper, 14 2010. UNDP. Available at: http://hdr.undp.org/sites/default/files/hdrp_2010_14.pdf ${ }^{12}$ UN Sustainable Development Goals Knowledge Platform, Gender Equality and Women's Empowerment. Available at https://sustainabledevelopment.un.org/topics/genderequalityandwomensempowerment (last accessed 4 March 2019).
} 
${ }^{13}$ United Nations Environment Programme. Convention on Biodiversity. 1992. Available at https://www.cbd.int/convention/ (last accessed 4 March 2019).

${ }^{14}$ See for example, Braidotti R, Charkiewicz E, Hausler S, Wieringa S. Women, the Environment and Sustainable Development, Towards a Theoretical Synthesis. London: Zed Books; 1994.

${ }^{15}$ See note 12 . UN SDGs.

${ }^{16}$ Guideline 18, Individuals in hierarchical relationships. Council for International Organizations of Medical Sciences (CIOMS). International Ethical Guidelines for Health-related Research Involving Humans. 4th ed. Geneva. 2016. p.57. Available at https://cioms.ch/wp-content/uploads/2017/01/WEB-CIOMSEthicalGuidelines.pdf (last accessed 4 March 2019).

17 "Women's sexual and reproductive health is related to multiple human rights, including the right to life, the right to be free from torture, the right to health, the right to privacy, the right to education and the prohibition of discrimination." United Nations Office of the High Commissioner on Human Rights. Women's Rights are Human Rights. 2014. http://www.ohchr.org/Documents/Events/WHRD/WomenRightsAreHR.pdf (last accessed 4 March 2019).

${ }^{18}$ Baptiste D, Kapungu C, Khare MH, Lewis Y, Barlow-Mosha L. Integrating women's human rights into global health research: an action framework. Journal of Women's Health (Larchmt) 2010;19(11):2091-9.

${ }^{19}$ See note 12 . UN SDGs.

20 See note 3. Mazure, Jones 2015.

${ }^{21}$ See note 4. Liu, Dipietro Mager 2016.

${ }^{22}$ For example, the US National Institutes of Health (NIH) 2015 funding guideline. Its core element is the classification of sex as a biological variable, taking the potentially relevant sex/gender related anatomical and physiological characteristics into account, as a key element of rigorous study design. National Institutes of Health Office of Extramural Research. Consideration of Sex as a Biological Variable in NIH-funded Research. Notice Number: NOT-OD-15-102: June 9, 2015. Available at https:/grants.nih.gov/grants/guide/noticefiles/NOT-OD-15-102.html (last accessed 4 March 2019).

${ }^{23}$ Drake C, Gahagan J. Working "Upstream": Why We Shouldn't Use Heterosexual Women as Health Promotion Change Agents in HIV-Prevention Interventions Aimed at Heterosexual Men. Health Care for Women International 2015;36:11:1270-89.

${ }^{24}$ European Commission. Horizon 2020. Ethics. Available at https://ec.europa.eu/programmes/horizon2020/en/h2020-section/ethics (last accessed 4 March 2019).

${ }^{25}$ Schroeder D, Cook J, Hirsch F, Fenet S, Muthuswamy V. (2018). Introduction. In: Schroeder D, Cook J, Hirsch F, Fenet S, Muthuswamy V, editors. Ethics Dumping - Case Studies from North-South Research Collaborations. Springer Open; 2018. p.2.

${ }^{26}$ World Medical Association. Declaration Of Helsinki - Ethical Principles For Medical Research Involving Human Subjects 2013. Available at https://www.wma.net/policies-post/wma-declaration-of-helsinki-ethicalprinciples-for-medical-research-involving-human-subjects/ (last accessed 4 March 2019).

${ }^{27}$ See note 16. CIOMS 2016.

${ }^{28}$ E.g. The TRUST Project. The Global Code of Conduct for Research in Resource-Poor Settings. 2018. Available at http://www.globalcodeofconduct.org/ (last accessed 4 March 2019).

${ }^{29}$ Schroeder D, Cook J, Hirsch F, Fenet S, Muthuswamy V, editors. Ethics Dumping: Case Studies from NorthSouth Research Collaborations. Springer Open; 2018. Available at https://www.springer.com/gb/book/9783319647302 (last accessed 4 March 2019).

${ }^{30}$ van Niekerk J, Wynberg R. (2018). Human Food Trial of a Transgenic Fruit. In: Schroeder D, Cook J, Hirsch F, Fenet S, Muthuswamy V, editors. Ethics Dumping - Case Studies from North-South Research Collaborations. Springer Open; 2018. p. 91-98.

${ }^{31}$ Food security is the condition in which all people, at all times, have physical, social and economic access to sufficient safe and nutritious food that meets their dietary needs and food preferences for an active and healthy life. See http://www.fao.org/cfs/home/about/en/ (last accessed 4 March 2019).

32 Food sovereignty is asserted by advocacy groups as right of peoples to healthy and culturally appropriate food produced through ecologically sound and sustainable methods, and their right to define their own food and agriculture systems. See https://en.wikipedia.org/wiki/Food sovereignty (last accessed 4 March 2019).

${ }^{33}$ Community Alliance for Global Justice. Agra Watch Press Release. Over 57,000 Express Concern with Human Feeding Trials of GMO Bananas. Seattle: February 11, 2016 https://cagj.org/2016/02/agra-watch-pressrelease-over-57000-express-concern-with-human-feeding-trials-of-gmo-bananas/ (last accessed 4 March 2019). 
${ }^{34}$ Li S, Nugroho A, Li S, Rocheford T, White WS. Vitamin A equivalence of the $\beta$-carotene in $\beta$-carotenebiofortified maize porridge consumed by women. The American Journal of Clinical Nutrition 2010;92(5):110512.

35 Lewis T. A group of scientists plans to pay young women $\$ 900$ to eat genetically modified bananas. Business Insider. 2016 Feb 23: http://uk.businessinsider.com/scientsts-are-paying-people-to-eat-gmo-bananas-20162 ? $r=U S \& I R=T$ (last accessed 4 March 2019).

${ }^{36}$ Leys T. ISU still plans GMO banana trial, despite controversy. Des Moines Register. 2016 Feb 17: http://www.desmoinesregister.com/story/news/health/2016/02/17/isu-still-plans-gmo-banana-trial-despitecontroversy/80507378/ (last accessed 4 March 2019).

${ }^{37}$ Available at http://www.banana21.org/about.html (last accessed 4 March 2019).

38 World Health Organisation. Micronutrient deficiencies: vitamin A deficiency. Available at http://www.who.int/nutrition/topics/vad/en/ (last accessed 4 March 2019).

${ }^{39}$ Macklin, R. Double Standards in Research in Developing Countries. Cambridge: Cambridge University Press; 2004.

${ }^{40}$ See note 16. CIOMS 2016.

${ }^{41}$ Bompart F. Healthy Volunteers for Clinical Trials in Resource-Poor Settings: National Registries Can Address Ethical and Safety Concerns. Cambridge Quarterly of Healthcare Ethics 2019;28(1):134-143.

42 Leentjens AFG, Levenson JL. Ethical issues concerning the recruitment of university students as research subjects. Journal of Psychosomatic Research 2013;75(4):394-8.

43 Joint Economic Committee United States Congress. Apr 2016. Available at https://www.jec.senate.gov/public/ cache/files/0779dc2f-4a4e-4386-b847-9ae919735acc/gender-payinequality----us-congress-joint-economic-committee.pdf (last accessed 4 March 2019).

${ }^{44}$ Srinivasan S, Johari V, Jesani A. Cervical Cancer Screening in India. In: Schroeder D, Cook J, Hirsch F, Fenet S, Muthuswamy V, editors. Ethics Dumping - Case Studies from North-South Research Collaborations. Springer Open; 2018. p. 33-47.

45 Bayer R. The Debate over Maternal-Fetal HIV Transmission Prevention Trials in Africa, Asia, and the Caribbean: Racist Exploitation or Exploitation of Racism? American Journal of Public Health 1998;88(4):567-70. ${ }^{46}$ Angell, M. The Ethics of Clinical Research in the Third World. New England Journal of Medicine 1997;337(12): 847-849.

${ }^{47}$ See note 16 . CIOMS 2016. Guideline 15 re poverty and group vulnerability.

48 UN Committee on the Elimination of Discrimination against Women (CEDAW). Available at

https://sustainabledevelopment.un.org/index.php?page=view\&type=30022\&nr=108\&menu=3170 (last accessed 4 March 2019).

${ }^{49}$ Schroeder D, Gefenas E. Vulnerability - Too Vague and Too Broad?. Cambridge Quarterly of Healthcare Ethics 2009;18(2):113-21.

${ }^{50}$ Alverez-Castillo F, Cook Lucas J, Cordillera Castillo, R. Gender and Vulnerable Populations in Benefit Sharing: An Exploration of Conceptual and Contextual Points. Cambridge Quarterly of Healthcare Ethics 2009;18(2):130-137. p132.

${ }^{51}$ See note 16 . CIOMS 2016. Guideline 15 re vulnerability and contextual factors such as lack of access to medical care.

52 See note 16. CIOMS 2016. For example CIOMS Guideline 18 refers to how in some settings women may be exploited in research through some level of coercion to take part (lack of truly informed consent), become socially vulnerable when participating in research due to their subordinate social position, or put at heightened social, physical or legal risk when participating.

${ }^{53}$ See note 44. Bayer 1998. 